\title{
Commentary: In the management of aortic stenosis volume is not enough
}

\author{
J. James Edelman, PhD, MBBS(Hons), Hiroto Kitahara, MD, and Vinod H. Thourani, MD
}

\footnotetext{
From the Department of Cardiac Surgery, MedStar Heart and Vascular Institute, Georgetown University, Washington, DC.

Disclosures: Dr Thourani is a researcher and consultant for Edwards Lifesciences. All other authors have nothing to disclose with regard to commercial support.

Received for publication July 20, 2019; accepted for publication July 22, 2019; available ahead of print Sept 14, 2019.

Address for reprints: Vinod H. Thourani, MD, Department of Cardiac Surgery, MedStar Heart and Vascular Institute, Georgetown University, 110 Irving St, Suite 6D15G, Washington, DC 20010 (E-mail: vinod.h.thourani@ medstar.net).

J Thorac Cardiovasc Surg 2020;159:1260-1

$0022-5223 / \$ 36.00$

Copyright (C) 2019 by The American Association for Thoracic Surgery

https://doi.org/10.1016/j.jtcvs.2019.07.067
}

The inverse relationship between procedure volume and outcomes has been demonstrated in a number of general and cardiac surgical procedures, including valvular and coronary artery bypass surgery. ${ }^{1-3}$ Even before Vemulapalli and colleagues ${ }^{4}$ demonstrated a similar relationship in transcatheter aortic valve replacement (TAVR), volume (for surgical aortic valve replacement and percutaneous coronary intervention) had been used as a proxy for quality by the Centers for Medicare and Medicaid Services (CMS) for the establishment of TAVR programs.

Kurlansky and Bagiella ${ }^{5}$ elegantly discuss the volumeoutcome relationship in TAVR that was recently reported in the New England Journal of Medicine. ${ }^{4}$ The inverse relationship between volume and outcome is clear from the smoothed curves presented in this study and supports the use of volume as a proxy for quality. However, as Kurlansky and Bagiella point out, where this proxy fails is in identifying the many excellent-quality, low-volume centers or the poorly performing high-volume centers. Using prior outcomes as a quality metric for a low-volume center can be similarly problematic because a single mortality can inflate an otherwise well-performing institution's outcomes to alarming levels due to the low denominator.

A recently published American Association for Thoracic Surgery, American College of Cardiology, Society for Cardiovascular Angiography and Interventions, and Society of Thoracic Surgeons (AATS/ACC/SCAI/STS) Expert Consensus Systems of Care Document acknowledged these difficulties and placed an emphasis on "direct measures of quality of care," including risk-adjusted mortality and alternative outcomes (such as quality of life) measured in the hospital, at 30 days, and (ultimately) at 1 year. ${ }^{6}$ The AATS/ACC/SCAI/STS Expert Consensus Systems of Care Document proposes that minimum volume requirements be used to ensure that a program has adequate statistical power to apply quality metrics and maintain effective processes of care. ${ }^{6}$ An effective multidisciplinary heart

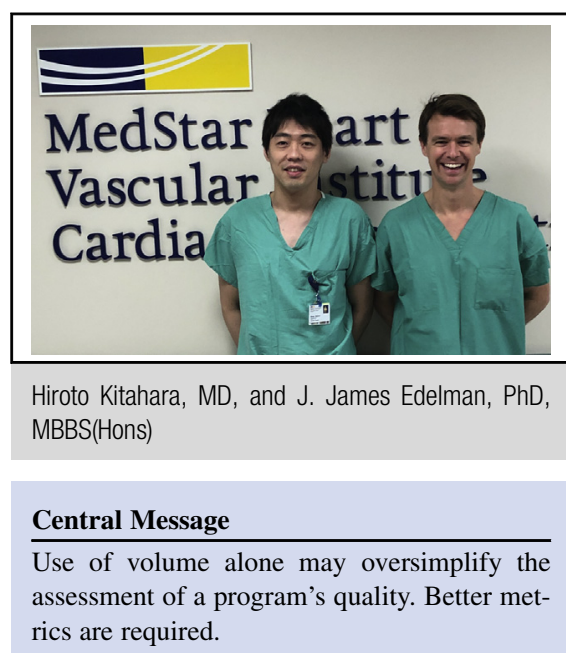

See Article page 1258 .

team and the incorporation of shared decision making with patients are also recommended as quality requirements. ${ }^{6} \mathrm{CMS}$ has recently updated requirements to establish and maintain TAVR programs. Volume requirements for established programs have decreased, requiring $\geq 50$ aortic valve replacements (TAVR or surgical) per year, including $\geq 20$ TAVR procedures. The CMS coverage is broadly in line with the recommendations of the AATS/ ACC/SCAI/STS Expert Consensus Systems of Care Document.

With the imminent, anticipated expansion of TAVR to low-risk patients, the use of low-frequency events such as mortality and stroke to measure the quality of low-volume programs will be even more difficult. Especially because the number of low-volume TAVR programs is expected to increase. Given that the expectations of excellent results are high in this low-risk patient population, never before has the measurement of quality been more important for the management of aortic stenosis. We agree with Kurlansky and Bagiella ${ }^{5}$ that the use of volume alone, whilst convenient, may oversimplify the assessment of quality. The metrics being developed by the STS/ACC Transcatheter Valve Registry should be a better measure. However, volume cannot be ignored because it increases confidence that outcomes are a true representation of a program's performance; it is easier to detect a poorly performing highvolume center than to detect a poorly performing lowvolume center. Next, careful thought should be put toward how to rehabilitate an underperforming program. 
Ultimately, information about the quality of a program should be available to assist patients in their decision about where their aortic valve disease is treated.

\section{References}

1. Birkmeyer JD, Siewers AE, Finlayson EVA, Stukel TA, Lucas FL, Batista I, et al. Hospital volume and surgical mortality in the United States. N Engl J Med. 2002; 346:1128-37.

2. Chikwe J, Toyoda N, Anyanwu AC, Itagaki S, Egorova NN, Boateng P, et al. Relation of mitral valve surgery volume to repair rate, durability, and survival. J Am Coll Cardiol. 2017;69:2397-406.

3. Vassileva CM, McNeely C, Spertus J, Markwell S, Hazelrigg S. Hospital volume, mitral repair rates, and mortality in mitral valve surgery in the elderly: an analysis of US hospitals treating Medicare fee-for-service patients. J Thorac Cardiovasc Surg. 2015;149:762-8.e1.

4. Vemulapalli S, Carroll JD, Mack MJ, Li Z, Dai D, Kosinski AS, et al. Procedural volume and outcomes for transcatheter aortic-valve replacement. $N$ Engl J Med. 2019;380:2541-50.

5. Kurlansky P, Bagiella E. Knowledge in numbers. J Thorac Cardiovasc Surg. 2020; 159:1258-9.

6. Bavaria JE, Tommaso CL, Brindis RG, Carroll JD, Deeb GM, Feldman TE, et al 2018 AATS/ACC/SCAI/STS expert consensus systems of care document: operator and institutional recommendations and requirements for transcatheter aortic valve replacement: a joint report of the American Association for Thoracic Surgery, American College of Cardiology, Society for Cardiovascular Angiography and Interventions, and Society of Thoracic Surgeons. J Am Coll Cardiol. 2019; 73:340-74. 